\title{
Avaliação de implantação da ferramenta de controle de estoques curva $A B C$ em uma empresa de produtos agropecuário
}

O presente trabalho tem como fundamento propor sugestão de aplicabilidade da ferramenta Curva ABC no processo de gestão de estoque de uma empresa agropecuária com o intuito de melhorar o desempenho das operações de atividades rotineiras da empresa. Foi percebida uma certa ineficiência da empresa em relação a um controle mais acurado de suas operações, o que pode gerar transtornos na hora da comercialização além de perdas no sistema financeiro da organização. $O$ trabalho teve além da proposta do uso da curva $A B C$ o interesse em compreender as causas que levam a empresa ao excesso de estoque de alguns itens o que pode tornar os mesmos obsoletos no estoque. Objetivou-se ainda identificar as principais falhas em relação ao controle de estoque e verificação da eficiência da aplicabilidade da curva $A B C$ no sistema de gestão de estoque. Para realização desta etapa foi feita observação no local para checagem dos fatos e, para o desenvolvimento foram realizados levantamentos bibliográficos referentes ao tema. Para se obter bons resultados financeiros na organização é indispensável que os setores de estoques estejam em sintonia com as demais atividades da empresa e os funcionários devem estar aptos ao uso do sistema. O uso de um sistema operacional que disponibiliza o uso da ferramenta do tipo curva $A B C$ irá auxiliar não somente no processo de controle dos estoques, mas também propiciará benefícios para o sistema financeiro da loja. Dessa maneira, foi identificado durante o período de observação que a empresa apresenta certo descompasso entre o que vende e o que estoca, ficando muitas vezes produtos encalhados que acabam vencendo a sua validade.

Palavras-chave: Ferramenta ABC; Avaliação; Controle.

\section{Evaluation of the implementation of the $A B C$ curve control tool in an agricultural products company}

\begin{abstract}
The present paper had as objective to propose the application of the $A B C$ curve tool to the management process in a stock of agricultural company to think about the increase of the daily activities of the company. An ineffectiveness was observed when it comes to efficient control in its operations, and it can cause marketing disorder and excessive losses in the financial organization system. In addition to the proposal of the ABC curve, the article intended to understand the causes that promote an excess of stock of some products, becoming the same obsolete in the stock. The objective was also to identify the principal's flaws in the inventory control and to verify the effectiveness in the application of the $A B C$ curve system to manage the stock. To realize that the stage was made an observation on the spot, to verify facts, and a bibliographic research was developed compatible with the theme. To obtain good financial results in the organization, it is essential that the sectors are aligned with the other activities of the company and that employers can use the system. The operating system that uses the ABC curve of the tool would not only assist in the process and control of inventory, but would also bring benefits to the store's financial system. It was identified during the observation that the company has a mismatch between sales and inventory, and there may be times when products are idle and their expiration dates have expired.
\end{abstract}

Keywords: ABC Tool; Evaluation; Control.

Topic: Planejamento, Estratégia e Competitividade

Reviewed anonymously in the process of blind peer.
Received: 07/06/2020

Approved: 29/07/2020
Simone Ribeiro Peres (iD)

Instituto Federal Goiano, Brasil

http://lattes.cnpq.br/2487958733917661

http://orcid.org/0000-0001-7352-8664

simonedata1@hotmail.com

Juliano de Caldas Rabelo (iD

Instituto Federal Goiano, Brasil

http://lattes.cnpq.br/5054768054817475

http://orcid.org/0000-0003-3741-4488

juliano.rabelo@ifgoiano.edu.br

Maria Gláucia Dourado Furquim (it)

Instituto Federal Goiano, Brasil

http://lattes.cnpq.br/2681775689273863

http://orcid.org/0000-0001-7823-9546

maria.furquim@ifgoiano.edu.br
José Carlos de Sousa Júnior

Instituto Federal Goiano, Brasil

http://lattes.cnpq.br/9146562480275155

http://orcid.org/0000-0003-2578-8140

josecarlos.junior@ifgoiano.edu.br
Referencing this:

PERES, S. R.; RABELO, J. C.; FURQUIM, M. G. D.; SOUSA JÚNIOR, J. C. Avaliação de implantação da ferramenta de controle de estoques curva $A B C$ em uma empresa de produtos agropecuário. Revista Brasileira de Administração Científica, v.11, n.3, p.144-154, 2020. DOI: http://doi.org/10.6008/CBPC2179-684X.2020.003.0010 


\section{INTRODUÇÃO}

Com a chegada de novas tecnologias o mundo dos negócios ficou cada vez exigente em qualquer que seja o ramo de atividade, dessa forma também os consumidores estão mais rigorosos na escolha de um determinado serviço ou produto. Para atender um mercado consumidor tão exigente, as empresas tendem a adotar mecanismos que auxiliem na coordenação de determinadas funções ou operações, objetivando a viabilidade nos processos de governança e nas tomadas de decisões.

Fiabani (2015) aponta que atualmente as organizações estão em constantes mudanças, decorrente do processo de globalização e dos avanços tecnológicos, e que as empresas necessitam se adequar a um modelo mais ágil e eficiente para garantir assim a sua competitividade no mercado.

Tal inovação exigiu que as organizações se mantivessem em constante atualização com o seu mercado consumidor. Uma das tendências está voltada a identificar as necessidades e desejos desse mercado para depois satisfazê-las, o que de certa forma resultou em estoques mais enxutos, uma vez que a aceleração do mercado pode fazer com que um novo produto fique obsoleto antes mesmo de chegar ao cliente. (FIABANI 2015)

Com o intuito em aumentar a competividade no mercado e atingir novas fronteiras as empresas estão apostando no uso de ferramentas e técnicas no setor de gestão de estoques, objetivando assim o aumento da produção e a redução dos custos, pois estes representam em geral uma grande parte do capital investido no negócio (FIABANI, 2015).

Para auxiliar na gestão de controle de estoques a curva $A B C$ tem se se tornado uma aliada nos processos administrativos destes, pois a mesma de acordo com Souza et al. (2017), proporciona o apontamento de itens que tenham uma demanda maior e que precisam ser tratados de forma mais precisa em se tratando de estoques.

No entanto, para se obter bons resultados financeiros dentro de uma organização os estoques devem estar em total equilíbrio com as demais atividades do estabelecimento, pois para que produtos e serviços estejam sempre à disposição dos clientes no momento certo e na quantidade certa, é necessário que o gestor tenha conhecimento e condições suficientes na hora de suprirem as necessidades da empresa (SOUZA et al., 2017).

Dessa forma, a pesquisa permitiu presenciar o processo administrativo de mercadorias de uma empresa com atividades no ramo agropecuário, tendo como finalidade uma sugestão de melhoria no desempenho da gestão do controle de estoque através da proposta de implantação de sistema que traz em seu programa o uso da ferramenta curva $A B C$.

\section{MATERIAIS E MÉTODOS}

Para o desenvolvimento do trabalho foram realizados levantamentos bibliográficos através de livros, artigos e sites especializados no assunto com o intuito de esclarecer os conceitos apresentados no trabalho, pois para Pinheiro (2010), a metodologia é realizada através de algum material já publicado, onde se permite comprovar fatos ocorridos e já comprovados por outros autores. Também foi usado na elaboração do mesmo uma pesquisa de campo de caráter exploratório, onde para a coleta de dados foram feitos estudos através 
de observação no local da pesquisa, sendo o setor analisado uma loja de produtos agropecuários e similares.

De acordo com Hernández et al. (2013), a pesquisa de caráter exploratório serve para obter conhecimento de algo, ou de algum lugar, tornando o campo da pesquisa mais ampla onde se identifica novas situações ou problemas em que serão analisados e sujeitos a novos estudos. Já a pesquisa qualitativa compreende na escolha do método de pesquisa, nas análises do trabalho sob diferentes pontos não apenas em um único conceito, mas de forma a abranger várias ideias em um mesmo tema (FLICK, 2009). No caso deste trabalho as observações foram feitas diretamente na empresa durante um período de 100 horas, onde se pôde notar todo o processo de comercialização, a forma como são organizados os estoques, seja no controle de entrada reposição ou de saída de itens.

\section{REVISÃO TEÓRICA}

\section{Gestão de Estoques: Abordagem Conceitual}

Estoques são materiais ou insumos que as organizações mantêm com o objetivo de garantir a entrega imediata do produto para o cliente após a venda ou na fabricação de outros produtos assegurando para que a produção não seja interrompida por falta da matéria prima. Há vários conceitos para estoque, porém, essas definições basicamente se resumem na mesma ideia. Para Souza (2017), estoques são um conjunto de materiais que se encontram em uma situação de espera por um determinado período de tempo aguardando o momento oportuno para a sua comercialização.

Martelli et al. (2015) descreve que estoques não são considerados apenas produtos que estão armazenados em depósitos, devem considerar estes todo e qualquer material, seja ele, matéria prima, insumos, componentes, produtos em processos, produtos acabados, etc. que estejam não apenas estocados, mas que também estão disponíveis nas prateleiras à disposição dos clientes.

Para Santos (2013), os estoques constituem em uma maioria a composição do capital de uma empresa e quando parado, esses recursos consistem em grandes perdas no sistema financeiro do estabelecimento. Oliveira et al. (2016), aponta os estoques como itens relevantes que fazem parte em qualquer ramo de negócio, seja na área varejista, atacadista, serviços e até mesmo em residências, independentemente da quantidade.

É necessário que as organizações obtenham estoques, pois estes têm a função de gerar operações de natureza que compõem a produção, a venda ou serviços, e são fontes frequentes de problemas que podem ocasionar perdas no capital da empresa quando mal administrados (SILVA JUNIOR et al., 2012). Para se manterem competitivas em um mercado onde o consumidor está cada vez mais exigente, as empresas, necessitam de pleno conhecimento e dedicação no comando de cada departamento ou setor. Para Santos (2013), um dos setores que merece um destaque é a gestão do controle de estoques, pois estes são tão importantes para o sucesso da empresa que, quando mantidos em equilíbrio com os demais setores, isso significa a sustentabilidade do negócio. Cabe destacar que os estoques são sinônimo de custos para a organização e demandam atenção acerca do investimento direcionados para sua composição. "A 
necessidade de manter estoques acarreta uma série de custos às empresas. Os Japoneses, pioneiros nos estudos do just-in-time, consideram os estoques uma forma de desperdício".

\section{Curva $A B C$ : ferramental no processo de gestão de estoques}

A curva $A B C$ é um método bem antigo criado pelo economista italiano Vilfredo Pareto, que ao fazer uma análise da distribuição de renda dos italianos no século passado, notou que havia uma concentração de riqueza com um percentual de $80 \%$ para $20 \%$ da população da época, significando que a maior concentração de renda daquela época estava sob o comando de poucas pessoas (GOEBEL, 1996, citado por ARAGÃO et al., 2016). De acordo com Pereira (1999, citado por ARAGÃO et al., 2016), a curva ABC é bastante utilizada e muito eficiente no controle de estoques, pois através da mesma é possível identificar a necessidade de giro de cada item, facilitando assim a tomada de decisão para a escolha de qual produto deve levar em consideração na hora de serem efetuadas as compras para a empresa.

A aplicabilidade da Curva $A B C$ no controle de estoque, proporciona ao gestor, um estudo na tomada de decisão, apontando ao analista do setor o produto certo, a quantidade certa e o momento certo. Embasado nos resultados obtidos por meio da ferramenta aplicada o gestor irá consequentemente se beneficiar na utilização dos recursos financeiros e materiais, de forma otimizada evitando assim, aquisições desnecessárias e favorecendo a lucratividade. Assim, sendo a Curva $A B C$, é um modelo de ferramenta empregado muito eficiente, que contribui para a classificação de material estocado possibilitando a identificação de itens com menos e mais demanda e produtos que atingem mais e menos lucro (SOUZA, 2017). Para Dias (1995, citado por OLIVEIRA, 2011), a Curva ABC consiste na separação dos produtos do estoque em três grupos diferentes, como mostra o Quadro 1.

Quadro 1: Representatividade de estoque da ferramenta $A B C$.

\begin{tabular}{|l|l|l|}
\hline A & B & C \\
\hline $\begin{array}{l}\text { Maior demanda, produtos com } \\
\text { giro rápido e dão mais lucro para } \\
\text { a empresa. }\end{array}$ & $\begin{array}{l}\text { Média demanda, são itens, cujo a procura é } \\
\text { razoável, mas necessitam de atenção, pois, podem } \\
\text { tornar um produto do grupo A. }\end{array}$ & $\begin{array}{l}\text { Pouca demanda, com pouco giro, mas } \\
\text { necessário tê-los, porém, com menor } \\
\text { incidência no estoque. }\end{array}$ \\
\hline
\end{tabular}

Fonte: Dias (1995, citado por OLIVEIRA, 2011) adaptado por Peres et al. (2020).

Na gestão de estoques a curva $A B C$ é usada como uma ferramenta na indicação de quais produtos devem ser levados em consideração para a aquisição como: quando comprar, quantidade a ser adquirida para o estoque, prazo de validade desses produtos, demanda, acesso aos fornecedores se é rápido ou não, ou seja, a curva $A B C$ permite ao gestor um mapeamento instantâneo do estoque e consequentemente tornará mais viável as tomadas de decisões na hora de efetuarem as compras (SANTANA et al., 2017).

No processo de organização, nota-se a eficiência da aplicabilidade da curva $A B C$, pois com estoque sob controle evita-se prejuízos causados pela falta de conhecimento da real demanda de cada item a ser estocado no estabelecimento comercial, pois, produtos com maior índice de demanda consequentemente terão necessidade de uma reposição mais frequente, enquanto produtos com menos procura serão necessários estudos mais cautelosos durante o processo aquisitivo dos mesmos.

É importante que o gestor esteja atento às quantidades e ao ambiente onde o produto será 
armazenado e principalmente atento às datas de vencimento sendo que, muitos itens têm um período muito curto no prazo de validade. Os estoques são extremamente necessários e devem ser mantidos de acordo com a necessidade da organização, pois produtos estocados, devem permanecer em um local adequado conforme exigência de cada item no intuito de preservar a sua integridade, assegurando que os mesmos estejam em excelentes condições na hora da comercialização.

A Curva $A B C$ é uma ferramenta, que quando aplicada na gestão do controle de estoques permite identificar itens que necessitam de mais cautela ao serem adquiridos. Assim, Oliveira (2011) descreve que, através deste recurso o administrador poderá ter informações precisas em relação aos produtos de acordo com o grau de rotatividade, como por exemplo, mercadoria que dura mais na prateleira ou que sai mais rápido, que tem o custo mais elevado na aquisição ou menos elevado, que dê mais lucro ou menos lucro e etc. Para Santos (2013), a curva ABC tem a finalidade de identificar produtos relacionados com a procura e valores, que quando apontado esses dados, torna viável a realização de um controle mais específico de itens com custo mais elevado e a rotatividade do mesmo.

\section{Como elaborar a curva $\mathrm{ABC}$}

Maya et al. (2017) salienta a importância da utilização do sistema $A B C$ no funcionamento do controle de estoque, pois quando o administrador tem amplo conhecimento da demanda de cada produto dentro de seu estabelecimento, isso proporciona um controle eficiente e condições necessárias do suprimento de cada item. Ainda segundo os autores, a curva ABC é fundamental na classificação de produto, pois permite gerar dados que podem ser analisados com facilidade e distinguir níveis de controle de itens baseado em sua importância, o que significa que deve dar mais atenção àqueles produtos que dão mais lucro e tem um maior giro de mercado e ficar atento àqueles que têm menos procura.

Neste sentido, para que o gestor possa ter pleno conhecimento do estoque é fundamental alguns aspectos para a elaboração da Curva ABC. De acordo com Santana et al. (2017), alguns requisitos são importantes para a classificação da mesma, como catalogar os produtos com nome, código, preço, quantidade e etc. Por sua vez, Fiabani (2015), cita a Curva ABC como lei dos 20/80, ou seja, 20\% dos itens representam $80 \%$ do valor de consumo. $O$ autor ainda menciona que para elaborar a curva $A B C$, deve-se levar em consideração fatores fundamentais de informação que deem o embasamento para elaboração de uma tabela mestra, catalogando produtos por um determinado período, enumerando-os e quantificando-os quanto aos seus respectivos consumos e preços, assim como mostra o exemplo na tabela 1.

Tabela 1: Tabela mestre.

\begin{tabular}{|l|l|l|l|}
\hline Itens & Consumo por determinado período & Valor Unitário Atual & Total de consumo \\
\hline 1 & 20 & 20,00 & 400,00 \\
\hline 2 & 15 & 40,00 & 600,00 \\
\hline 3 & 12 & 18,00 & 216,00 \\
\hline 4 & 25 & 25,00 & 625,00 \\
\hline 5 & 10 & 15,00 & 150,00 \\
\hline
\end{tabular}

Fonte: Fiabani (2015), adaptado por Peres et al. (2020). 
Tabela 2: Representação do total de consumo acumulado.

\begin{tabular}{|l|l|l|l|l|l|}
\hline Itens & $\begin{array}{l}\text { Consumo por determinado } \\
\text { período }\end{array}$ & $\begin{array}{l}\text { Valor Unit. } \\
\text { Atual }\end{array}$ & $\begin{array}{l}\text { Total de } \\
\text { consumo }\end{array}$ & $\begin{array}{l}\text { Percentual do } \\
\text { consumo }\end{array}$ & $\begin{array}{l}\text { Total acumulado de } \\
\text { consumo }\end{array}$ \\
\hline 4 & 25 & 25,00 & 625,00 & 31,39 & 625,00 \\
\hline 2 & 15 & 40,00 & 600,00 & 30,14 & $1.225,00$ \\
\hline 1 & 20 & 20,00 & 400,00 & 20,10 & $1.625,00$ \\
\hline 3 & 12 & 18,00 & 216,00 & 10,84 & $1.841,00$ \\
\hline 5 & 10 & 15,00 & 150,00 & 7,53 & $1.991,00$ \\
\hline
\end{tabular}

Fonte: Fiabani (2015), adaptado por Peres et al. (2020).

Ainda segundo, Oliveira (2011), deve-se calcular o valor total do consumo de cada item conforme Tabela 2. Após o cálculo dos valores acumulados, deve-se ordenar de forma decrescente e calcular percentual acumulado para posteriormente elaboração do gráfico que representará critérios de valor acumulado de consumo (FIABANI, 2015). Ver Tabela 3.

Tabela 3: Representação do percentual acumulado do consumo.

\begin{tabular}{|l|l|l|l|l|l|}
\hline Itens & $\begin{array}{l}\text { Consumo por determinado } \\
\text { período }\end{array}$ & $\begin{array}{l}\text { Valor Unit. } \\
\text { Atual }\end{array}$ & $\begin{array}{l}\text { Total de } \\
\text { consumo }\end{array}$ & $\begin{array}{l}\text { Total acumulado de } \\
\text { consumo }\end{array}$ & $\begin{array}{l}\text { de } \\
\text { acumulado }\end{array}$ \\
\hline 4 & 25 & 25,00 & 625,00 & 625,00 & 31,39 \\
\hline 2 & 15 & 40,00 & 600,00 & $1.225,00$ & 56,50 \\
\hline 1 & 20 & 20,00 & 400,00 & $1.625,00$ & 81,61 \\
\hline 3 & 12 & 18,00 & 216,00 & $1.841,00$ & 92,46 \\
\hline 5 & 10 & 15,00 & 150,00 & $1.991,00$ & 100,00 \\
\hline
\end{tabular}

Fonte: Fiabani (2015), adaptado por Peres et al. (2020).

Por último traçar uma linha representando uma curva a qual servirá de análise de produtos de representam o consumo e o valor do consumo (FIABANI, 2015). Ver gráfico 1.

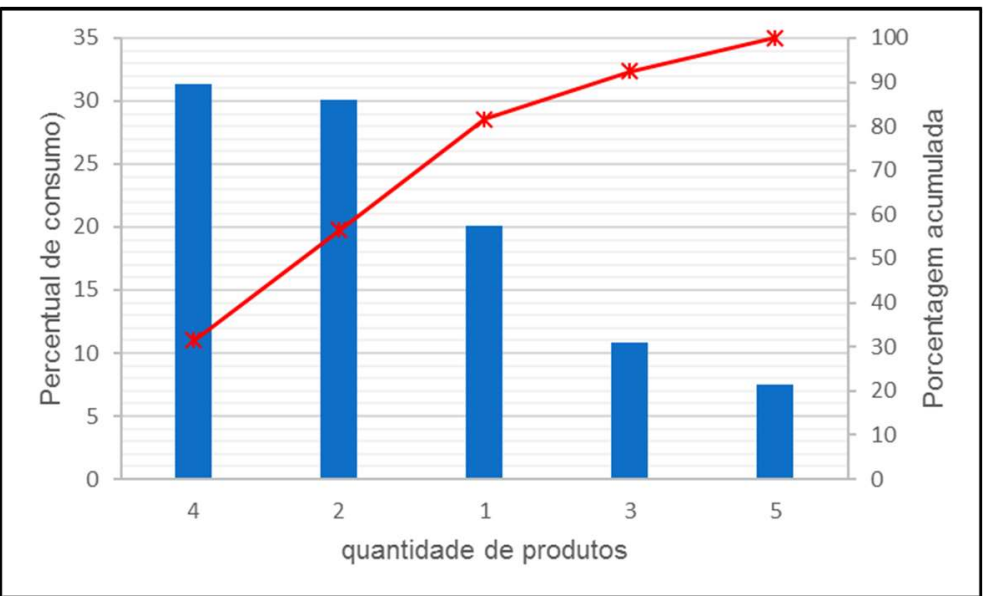

Figura1: Representação gráfica do consumo e do valor do consumo. Fonte: Fiabani (2015), adaptado por Peres et al. (2020).

Ainda de acordo com Fiabani (2015), os itens classificados com classe A correspondem até $75 \%$ de incidência de uso, itens de casse B correspondem entre $75 \%$ e $95 \%$ de incidência e de classe C vai de $90 \%$ a 100\% de incidência. Conforme a figura 1 em seu exemplo explicativo, percebe-se que os itens 4,2 e 1 são do grupo A e seu acumulado correspondem $80 \%$ de incidência de uso. 0 item 3 está entre aproximadamente $80 \%$ a $92 \%$, no entanto sua incidência de uso o mantém como item do grupo B. Já o item 5 pertence ao grupo C e sua incidência de uso vai de $92 \%$ a $100 \%$, ou seja, a frequência de saídas do estoque é de apenas 7,53\%. 


\section{RESULTADOS E DISCUSSÃO}

Para a realização do trabalho, foi feito um acompanhamento no processo de gestão de estoque de uma empresa do ramo de atividades agropecuária situada na região do Centro-Oeste goiano. É uma empresa já pioneira na região e com um potencial muito grande em desenvolvimento econômico e social, gerando emprego e renda na região.

A empresa se destaca pela ampla variedade de produtos e serviços, como medicamentos veterinários, insumos agrícolas, fertilizantes, equipamentos agrícolas, acessórios, assistência veterinária, manutenção de equipamentos, utensílios domésticos, vestuário bem como na fabricação de suplemento alimentar animal. A loja conta com apoio de três sócios proprietários, gerentes administrativos, auxiliares administrativos, vendedores balconistas, auxiliar de limpeza, auxiliar de serviços gerais, entregador e representantes de venda.

A empresa é composta pela matriz e mais cinco filiais que também estão situadas no centro-oeste goiano abrangendo uma área com um raio em torno de $200 \mathrm{~km}$, abastecendo a região com seus produtos e serviços do ramo da agropecuária, além da oferta de emprego e renda que proporciona à população de toda região. Embasado nos aspectos observados in loco, verificou-se uma certa ineficiência na gestão de estoque especificamente no controle de validade de medicamentos veterinários e de defensivos agrícolas, gerando assim prejuízos financeiros à empresa. Outro problema verificado é a produção de suplementação alimentar animal, pois este, deve ser analisado com mais cautela, levando-se em consideração a real demanda de produção da ração e também a compra, reposição de defensivos agrícolas e produtos veterinários.

Buscou-se com a observação das atividades da empresa compreender qual seria a melhor ferramenta de gestão de estoques para resolver os problemas de gestão do estoque, pois o processo de organização dentro de uma empresa é considerado um fator primordial e a busca por novas tecnologias que auxiliem na solução de problemas é cada vez mais necessária. Novos recursos e novos modelos podem facilitar todas as operações de funcionamento fazendo com que a empresa se adeque ao processo de competitividade e demanda do mercado (MARTILLI et al., 2015).

Diante do contexto do processo de organização interna da empresa nasce a necessidade de aplicar métodos que auxiliem no gerenciamento das atividades na gestão do estoque, objetivando a melhoria da eficiência, do desempenho e na busca por melhores resultados. A gestão eficiente no controle de estoques é indispensável para qualquer tipo de atuação dentro das organizações (MARTELLI et al., 2015).

Teixeira et al. (2016), aponta que um bom gerenciamento no controle de estoques não só customiza tempo e desempenho nas vendas como também é fundamental na redução dos custos monetários que podem ser afetados negativamente se o estoque não tiver um giro adequado para atender as demandas de consumo de um determinado produto. Para um controle adequado de seus estoques cada empresa utiliza um método que auxilie nesse gerenciamento, permitindo assim mais atenção aos produtos com maior demanda e produtos com menor demanda, mas que também são necessários no estoque.

Mediante o período de observação percebeu-se a grandeza de um comércio ao qual vem se 
destacando com sua imensa oferta de serviços, produtos e insumos destinados à produtividade no campo, além de um amplo estoque de medicamentos veterinários, produtos de utilidades domésticas e vestuário da moda country.

Foi observado que há na empresa um depósito onde são armazenadas as mercadorias. A reposição de mercadorias nas prateleiras da loja é feita diariamente pelos balconistas, sempre no período da manhã. Cada vendedor além de ter a preocupação em atender bem os seus clientes também é responsável pela reposição e organização de mercadorias a fim de deixar que o visual da loja se mantenha sempre em boa harmonia. Cada atendente é responsável por um setor de produto ou serviço e também é responsável pela gestão e controle destes.

O deslocamento do atendente para a reposição e contagem de produtos que estão em falta nas prateleiras ocorre simultaneamente ao período em que o mesmo se encontra à disposição de atendimento ao cliente, sendo assim essa tarefa acaba ocasionando sobrecarga ao vendedor, causando the problemas que afetam o seu desempenho na sua função principal dentro da empresa, que é a de vender. $O$ ideal seria que a firma contratasse um almoxarife, profissional exclusivo para reposição e contagem dos estoques.

O almoxarife, é o responsável por toda atividade administrativa do almoxarifado, desde a conferencia de uma nota fiscal com o pedido de compras, a guarda do estoque físico e das informações representadas no sistema de gestão do almoxarifado, as entradas e saídas dos materiais, arrumação e segurança das pessoas que ali trabalham e, sobretudo, pela garantia das acuracidades dos dados registrados no sistema. Dentro de um almoxarifado o profissional deve zelar pelas movimentações de materiais, pelo seu inventário, analisar os indicadores de controle de sua gestão e manter o controle orçamentário dentro do autorizado. (PAOLESCHI, 2009, citado por SILVA et al., 2017)

Ainda de acordo com Silva et al. (2017) o almoxarifado é um local especifico onde deve permanecer as mercadorias enquanto aguarda o momento oportuno até o seu destino final e que sua função é a de estocar de forma segura as mercadorias para que não aconteça nenhum tipo de perda, mantendo assim a preservação e a integridade de cada produto ali depositado. Com um profissional responsável somente pelo estoque e outro somente pelas vendas, ambos desempenhariam seu papel com mais dedicação e comprometimento para com a função, além de tornarem o trabalho de venda mais eficiente.

Durante o período de observação foram identificados vários departamentos na empresa, como por exemplo, uma oficina de equipamentos, visto que a loja trabalha com venda de alguns pequenos equipamentos agrícolas, como motosserra, furadeira, etc., a mesma se dispõe de uma oficina que atua na manutenção e conserto desses equipamentos. Também nesse caso um balconista é responsável pela assistência técnica do equipamento quando há algum desses necessitando de manutenção, A oficina não conta com um profissional especializado para exercer essa função de manutenção e organização da mesma, e isso faz com que essa atividade seja ineficaz e contraproducente.

Como a empresa é do ramo de produtos agropecuários há na loja uma câmara fria para armazenamento de vacinas que é monitorada diariamente por um vendedor e fiscalizada semanalmente por um agente da Agência Goiana de Defesa agropecuária (AGRODEFESA). Esse monitoramento se deve ao fato 
de que a temperatura deve ser ao tipo de produto que são perecíveis diante de temperaturas mais elevadas.

A empresa possui profissionais que atuam nas áreas agronômicas e veterinárias e os mesmos estão disponíveis para consultoria e emissão de receituários aos produtores, já que a empresa trabalha com produtos como pesticidas, agrotóxicos e medicamentos veterinários. Possui também uma fábrica de suplementação alimentar animal, como ração e proteína para bovinos, ração para suíno e aves, a qual abastece a loja matriz e também as filiais, sendo o mesmo um produto de muita demanda. Porém, foi constatado em muitas vezes, que a oferta não atende a procura, ocasionando assim vários transtornos, como o cancelamento de vendas por exemplo.

Portanto, notou-se durante o período de observação que venda de produtos, principalmente os suplementos para animais eram efetivados, mas que não havia em estoque e somente quando o cliente ia fazer a retirada desse produto no depósito era constatado a ausência do mesmo. Sendo assim, o cliente com a ordem de compra nas mãos voltava até o balcão de atendimento para que o vendedor pudesse cancelar o pedido.

A sugestão de implantação de um sistema de controle mais rigoroso impediria que fatos como estes citados acima acontecessem, evitando assim desconfortos para os clientes, proporcionando mais segurança para os funcionários e para loja, evitando assim, falhas no atendimento. Diante de todos os fatos discriminados é perceptível que a empresa precisa dar ênfase para a gestão do controle de estoques de medicamentos e derivados, pesticidas e suplementos animais, pois, estes são itens de maior demanda e de alto giro no estoque.

Como já mencionado anteriormente o controle de estoque de medicamentos veterinário da empresa é de responsabilidade de um vendedor o qual dispende seu tempo de atendimento ao cliente para assegurar que não haja falha na disponibilidade do produto, e isso ocasiona uma sobrecarga a esse funcionário por dividir sua principal tarefa com outras atividades da empresa.

Como toda empresa, há alguns itens com rotatividade baixa, com uma possibilidade de perdas muito grande, em especial os medicamentos veterinários e pesticidas, pois alguns apresentam prazo de validade muito curto. Cabe à empresa utilizar algum software que faça todo o gerenciamento do estoque, desde entrada de produtos, movimentação e saída, estes softwares apresentam ferramentas que conseguem fazer levantamentos estatísticos sobre a rotatividade de produtos através da Curva $A B C$, como exemplo pode-se seguir os procedimentos do software Enterprise Resource Planning (ERP).

O sistema EPR é um software incorporado nos mecanismos de gestão da empresa que proporciona reunir em um único sistema as soluções administrativas de vários departamentos da instituição, dispensando assim a necessidade do uso de várias ferramentas paralelas utilizadas na organização de gerenciamento (SISPRO-Empresa de Software Empresarial).

Algumas empresas disponibilizam softwares de gerenciamento de estoques, onde como o programa NEX por exemplo, que oferece programas que otimiza o controle de estoque de forma fácil e eficiente através da análise da Curva ABC. O programa NEX disponibiliza em seu sistema a função que gera relatório por meio da Curva ABC facilitando assim a análise de produtos e classificando-os de acordo com o grau de rotatividade 
(NEXTAR).

Para ser mais preciso no gerenciamento dos estoques, estes devem ser divididos em três grupos de produtos, e a maneira mais fácil de definir quais itens compõem esses grupos é gerando um relatório de Curva ABC. No programa NEX há uma aba em que inserindo corretamente todos os dados necessários, irá gerar automaticamente um modelo para análise (NEXTAR). A Figura 2 representa um exemplo de relatório.

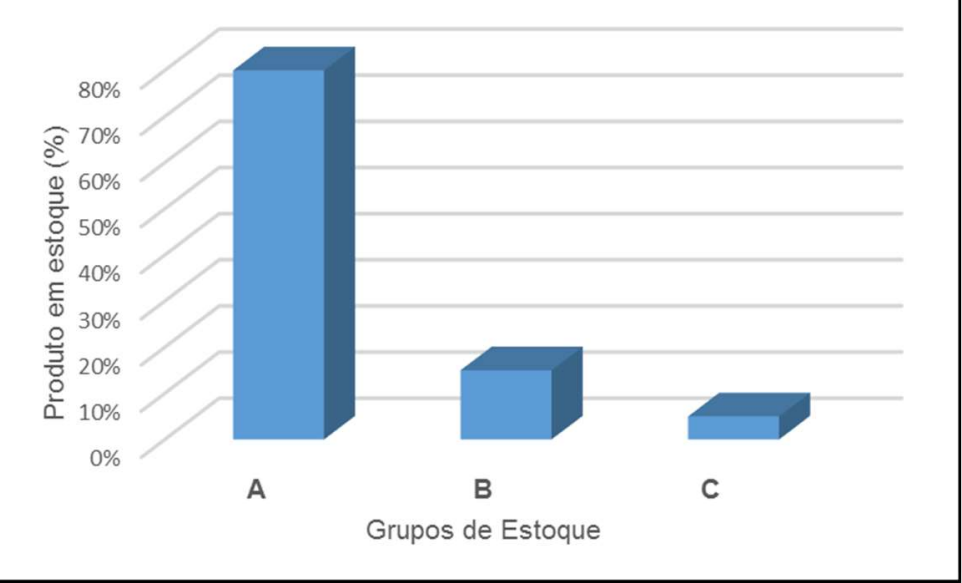

Figura 2: Representatividade de grupos de mercadorias no estoque. Fonte: NEXTAR adaptado por Peres et al. (2020).

Ao implantar um software com sistemas integrados que façam levantamentos estatísticos como a ferramenta $A B C$, a empresa não se beneficiará somente nas operações de controle de estoque, mas também de todo o conjunto de operações e transações realizadas em todos os departamentos da organização.

A empresa observada possui em suas dependências um software operacional, porém, não se sabe o motivo pelo qual o mesmo não aponta dados necessários para análise de um controle mais preciso. É indispensável a implantação de um sistema que dê suporte mais eficiente, mas não necessariamente o programa sugerido acima, pois este é apenas para exemplificar a importância de um sistema completo que controla e fornece suporte a todas as operações para todos os setores da empresa.

\section{CONCLUSÕES}

Percebe-se na organização não havia um controle acurado dos estoques, e constatou-se que a ferramenta de curva $A B C$ seria ideal para gerenciar a situação, evitando compras desnecessárias como também a perda de produtos vencidos, como também foi constatado falta de mão obra especializada no controle de estoques e na manutenção de equipamentos.

No entanto, fica explicito que a loja deixa a desejar em tarefas consideradas importantes quanto ao controle de estoque, pois nota-se, que durante o processo de comercialização há falhas no sistema de comunicação entre vendas e mercadorias estocadas, causando assim transtornos que geram desgastes aos funcionários bem como prejuízos financeiros à empresa. Com a contratação de profissionais capacitados para desenvolver atividades especificas a empresa tornaria as operações mais eficientes tornando mais viável o desempenho das tarefas das pessoas responsáveis por cada departamento ali existente.

Sugere-se então que a empresa disponha de um gestor exclusivo para o gerenciamento do estoque e que o mesmo deve ser treinado e disposto, que apresente conhecimento amplo na área, para que possa 
desenvolver um trabalho de excelência, bem como um profissional da área de manutenção de equipamentos, tornando possível a ligação entre setores.

\section{REFERÊNCIAS}

ARAGÃO A. M. S.; SANTOS, D. S.; MONTEIRO, L. F.. Aplicação da Curva $A B C$ em uma Empresa do setor Atacadista do Estado de Sergipe. In: ENCONTRO NACIONAL DE ENGENHARIA DE PRODUÇÃO, 36. Anais. João Pessoa: ENEGEP, 2016.

FIABANI, M.. Análise do Processo de Gestão de Estoques da Agropecuária Alfa Matriz. Monografia (Bacharelado) Universidade Federal da Fronteira Sul, Chapecó, 2015.

FLICK, U.. Métodos de pesquisa. Introdução à pesquisa qualitativa. 3 ed. Porto Alegre: Artmed, 2009.

HERNÁNDEZ, S. R.; COLLADO, C. F.; LUCIO, M. D. P. B.. Metodologia de pesquisa. 5 ed. Porto Alegre: PENSO, 2013.

MARTELLI, L. L.; DANDARO, F.. Planejamento e controle de Estoque nas Organizações. Revista Gestão Industrial, Ponta Grossa, v.11, n.2, p.170-185, 2015.

MAYA, L. M.; CRUZ, C. A. B.; OLIVEIRA, C. R.; FRAGA, É. E. A.. $A$ importância da ferramenta curva $A B C$ no gerenciamento de estoque. Produzir com qualidade na quantidade e no tempo certo maximizando o uso de recursos e minimizando os desperdícios. In: SIMPÓSIO DE ENGENHARIA DE PRODUÇÃO DE SERGIPE, 9. Anais. SIMPROD, 2017. p.378388.

OLIVEIRA, C. M.. Curva ABC na Gestão de Estoque. Educação e Pesquisa: A produção do conhecimento e a formação de pesquisadores. In: ENCONTRO CIENTIFICO E SIMPÓSIO DE EDUCAÇÃO UNISALISIANO, 3. Anais. 2011.

OLIVEIRA, P. M.; SOUZA, R. S.; SILVA, F. M.; LACERDA, V. S. S.. Os Desafios para a Gestão de Estoques em Micro e Pequena Empresas: um estudo de caso. In: SIMPÓSIO DE EXCELÊNCIA EM GESTÃO E TECNOLOGIA, 8. Anais. 2016.
PINHEIRO, J. M. S.. Da iniciação cientifica ao TCC: uma abordagem para os cursos de tecnologia. Rio de Janeiro: Ciência Moderna, 2010.

RODRIGUES, A. J.. Metodologia cientifica. Completo e Essencial para a Vida Universitária. São Paulo: AVERCANP, 2006.

SANTANA, M. L.; PIPER, H.. Proposta de melhoria de Layout e a curva $A B C$ no setor de estoques: um estudo de caso. Revista Ciência (In) Cena, v.1, n.5, p.30-50, 2017.

SANTOS, D. C. I.. Gestão de Estoques. FEMA, 2013.

SILVA, J. F. P. F.; MARQUES, K. M. R.; LUCAS, M. G.. A importância da gestão do almoxarifado. 2017.

SILVA JUNIOR, R.; HANZEL, M. E.. Gestão de Estoques: Fator decisivo para a lucratividade organizacional. Revista IberoAmericana de Engenharia Industrial, Florianópolis, v.4, n.7, p.100-117. 2012.

SOUZA, N. S.. Gestão de Estoques e sua Importância para as Organizações. Monografia (Bacharelado em Administração) - Anhanguera Educacional, Jacareí, 2017.

SOUZA, S. S.; SANTOS, P. C. C.; SILVA, V. A. R.. Estudo de gerenciamento de estoques da linha de rações da empresa Z.M. Agropecuária LTDA. Rev. Ciên. Empres. UNIPAR, Umuarama, v.18, n.2, p.311-347, 2017.

TEIXEIRA, T. A.; VERNINI, A. A.. Curva ABC como ferramenta para a gestão de estoques de uma doceria. In: JORNADA CIENTIFICA E TECNOLÓGICA DA FATEC DE BOTUCATU, 5. Anais. São Paulo, 2016.

A CBPC - Companhia Brasileira de Produção Científica (CNPJ: 11.221.422/0001-03) detém os direitos materiais desta publicação. Os direitos referem-se à publicação do trabalho em qualquer parte do mundo, incluindo os direitos às renovações, expansões e disseminaç̃oes da contribuição, bem como outros direitos subsidiários. Todos os trabalhos publicados eletronicamente poderão posteriormente ser publicados em coletâneas impressas sob coordenação da Sustenere Publishing da Companhia Brasileira de Produção Científica e seus parceiros autorizados. Os (as) autores (as) preservam os direitos autorais, mas não têm permissão para a publicação da contribuição em outro meio, impresso ou digital, em português ou em tradução. 